\title{
Conceptual Development and Case Data for a Modular, Personality-Based Treatment for \\ Borderline Personality Disorder
}

\author{
Shannon Sauer-Zavala \\ Matthew W. Southward \\ Caitlyn O. Hood \\ Sohayla Elhusseini \\ Martina Fruhbauerova \\ Nicole E. Stumpp \\ Stephen A. Semcho
}

Author note: Effort on this project was supported by the NIDA (T32 DA035200). This publication's contents are solely the responsibility of the authors and do not necessarily represent the official views of NIH. Data described in this manuscript represents an interim report of person-level analyses from an ongoing clinical trial; data are not available to share as the trial is not yet completed.

NOTE: This manuscript is currently in press at PD:TRT. Do not reproduce without permission. 


\begin{abstract}
Borderline personality disorder (BPD) is a heterogenous condition and variations in its presentation may be accounted for by individual differences in personality dimensions. Extant treatments for BPD are long-term and intensive; it is possible that prioritizing the personalitybased difficulties that underlie an individual's symptoms may improve the efficiency of care. This manuscript describes the conceptual background for the development of a novel, personality-based intervention for BPD (BPD Compass) informed by recent research on personality mechanisms maintaining this condition to address gaps left by existing treatments and be maximally efficient and disseminable. BPD Compass is a comprehensive, short-term package with a fully modular design that allows for personalization (e.g., all skills can be presented in isolation or in any order based on pre-treatment assessment). We discuss the theoretical background for its development, an overview of the skills included in the treatment, as well as preliminary efficacy data.
\end{abstract}

Keywords: borderline personality disorder, five factor model, treatment 


\section{Conceptual Development and Case Data for a Modular, Personality-Based Treatment for Borderline Personality Disorder}

Borderline personality disorder (BPD) is a costly and debilitating condition characterized by impairment across several areas of functioning (Sansone, 2004). In the Diagnostic and Statistical Manual of Mental Disorders (DSM-5), diagnostic criteria for BPD include emotional difficulties (labile affect and intense anger), interpersonal problems (efforts to avoid abandonment and unstable relationships), behavioral dysregulation (chronic suicidality, selfinjury, and other impulsive actions), identity disturbance (unstable self-image and chronic emptiness), and cognitive symptoms (transient dissociation and paranoia in response to stress; American Psychiatric Association [APA], 2013). A categorical diagnosis of BPD is assigned when a patient endorses five of nine criteria.

In addition to the categorical approach to diagnosing BPD, DSM-5 also includes a multidimensional diagnostic approach called the Alternative Model of Personality Disorders (AMPD; APA, 2013). Criterion A of the AMPD involves dimensional assessment of self (e.g., identity and self-direction) and interpersonal (e.g., empathy and intimacy) functioning, as difficulties in these areas are thought to define the core of personality disorders that distinguishes them both from healthy personality and other forms of psychopathology (Pincus, 2011). Criterion B involves the assessment of dimensional personality traits, organized into five broad domains (i.e., negative affectivity, detachment, antagonism, disinhibition, and psychoticism). Finally, Criteria $\mathrm{C}$ through $\mathrm{G}$ represent additional considerations when making a mental health diagnosis, including pervasiveness, stability, age of onset, discrimination from other mental disorders, and differentiation from the effect of substances, developmental state, or sociocultural environment. After establishing the presence of Criterion A above a threshold level, BPD is represented as elevations in Criterion B dimensions negative affectivity, disinhibition, and 
antagonism.

The AMPD conceptualization of BPD is similar to other dimensional of models of psychopathology. For example, the Hierarchical Taxonomy of Psychopathology (HiTOP; Kotov et al., 2017) includes a general psychopathology factor $(p)$ to characterize distress and impairment that may overlap with the AMPD’s Criterion A (Widiger et al., 2019). Moreover, HiTOP describes six broad spectra (i.e., internalizing, disinhibited externalization, antagonistic externalizing, detachment, thought disorder, and somatoform) that largely conform to Criterion B dimensions in the AMPD. From a HiTOP perspective, BPD is characterized by the internalizing (i.e., negative affectivity) and antagonistic externalizing (i.e., antagonism) spectra. Similarly, the dimensions captured in the AMPD's Criterion B are isomorphic with trait domains of five factor model of personality (FFM; Costa \& McCrae, 1990), a widely used paradigm for understanding individual differences.

\section{The AMPD and Extant Treatments for BPD}

Given that the field is moving toward a more dimensional, personality-based understanding of BPD (e.g., the ICD-11's formal adoption of a dimensional system for classifying personality disorders), it is important to consider how extant treatments for this condition, developed in the context of a categorical diagnostic system, remain relevant in a changing nosological landscape. We contend that existing interventions for BPD, in general, focus on a single AMPD Criterion B dimension of BPD (i.e., negative affectivity or antagonism). These treatments have amassed empirical support for their efficacy in addressing BPD (particularly for life-threatening symptoms; Kliem et al., 2010) and, importantly, at the group level, they do not appear to outperform each other (Cristea et al., 2017).

Dialectical behavior therapy (DBT; Linehan, 1993), perhaps the most well-known 
intervention for BPD, is designed to target emotional difficulties, analogous to the AMPD dimension of negative affectivity. Linehan (1993) describes BPD as a disorder of emotion dysregulation, characterized by high sensitivity to emotion-provoking stimuli, strong emotional responses, and slow return to baseline levels of arousal following a trigger. Although Linehan (1993) argues these emotional vulnerabilities are exacerbated by environmental factors (e.g., invalidating caregivers), DBT is primarily focused on addressing emotion dysregulation. DBT teaches patients cognitive-behavioral skills to tolerate (i.e., mindfulness, distress tolerance) and change (i.e., emotion regulation, interpersonal effectiveness ${ }^{1}$ ) emotions and the situations that elicit them. Meta-analytic findings suggest that DBT results in decreased suicidal thoughts and behaviors, hospitalizations, and anger (Kliem et al., 2010).

On the other hand, several treatments for BPD target relationship difficulties/antagonism (i.e., distrust, manipulativeness, oppositional tendencies; Mullins-Sweatt et al., 2012). Theorists have suggested that agreeableness, the opposite pole of antagonism, is functionally related to attachment styles that result from relationships with parents or other caregivers (Young et al., 2003). Specifically, low levels of agreeableness are thought to develop from insecure, ambivalent, and/or avoidant attachment styles (Bowlby, 1973) that, in adults, manifest as feeling vulnerable in relationships and lead to the seemingly protective behaviors that characterize externalizing psychopathology (e.g., acting cruel, isolating oneself, or seeking excessive admiration from others; Young et al., 2003). Individuals with BPD display high rates of insecure attachment styles (Agrawal et al., 2004), justifying the development of relationally-focused interventions for this condition, including psychodynamic treatments, such as transference--

\footnotetext{
${ }^{1}$ Although DBT's Interpersonal Effectiveness skill module targets interpersonal difficulties, it is largely focused on building assertiveness skills that will prevent unnecessary negative emotions in relationships. This module is not explicitly focused on addressing past interpersonal experiences that may contribute to mistrust in relationships (i.e., attachment difficulties).
} 
focused therapy (TFP; Clarkin et al., 2001; Kernberg, 1984) and mentalization-based treatment (MBT; Bateman \& Fonagy, 2004). Additionally, schema-focused therapy (SFT; Young et al., 2003 ) is a cognitive approach for personality disorders that includes techniques to challenge patterns of beliefs and behaviors about oneself and others (i.e., disconnection and rejection, impaired autonomy, impaired limits, other directedness). There is promising evidence that these interventions lead to reduced BPD symptoms and increased attachment security (Cristea et al., 2017; Levy et al., 2006; Vogt \& Norman, 2019).

\section{Limitations of Extant Treatments for BPD}

The currently available approaches for treating BPD are typically intensive, long-term, and technically sophisticated, requiring extensive training and support for therapists. However, BPD is a highly heterogenous condition with 256 possible symptom combinations for any given person (APA, 2013). Patients with BPD often present with less severe symptoms (Trull et al., 1997), and emerging evidence suggests that shorter courses of care (e.g., systems training for emotional predictability and problem solving [STEPPS; Black et al., 2004]; good psychiatric management [Gunderson et al., 2018]; internet-based psychoeducation [Zanarini et al., 2017]), as well as abbreviated or alternative delivery schemes (i.e., stepped care) of existing treatments (Laporte et al., 2018), are efficacious for this population. Given long waitlists for specialist care, it may be useful develop treatment approaches that can be easily tailored based on severity.

Another limitation of existing treatments for BPD is that they generally focus on either emotional difficulties/negative affectivity or attachment insecurity/antagonism. Given the variability observed in BPD presentations, idiographic mechanisms likely contribute to a particular patient's symptoms (Cardona et al., 2020). For example, if an individual's interpersonal difficulties are most strongly associated with neuroticism (e.g., stressors prompting 
strong emotions and temper outbursts serving to dampen negative affect), the treatment approach would be different than if this symptom resulted from high levels of antagonism (perhaps conferred through attachment difficulties from early life experiences). Of course, these putative mechanisms are not mutually exclusive, so an individual patient with BPD can have elevations on multiple personality dimensions. Given that extant treatments for BPD typically emphasize either emotional vulnerability/neuroticism or attachment insecurity/antagonism, these interventions may be incomplete for some individuals.

Finally, the AMPD conception of BPD (APA, 2013; Mullins-Sweatt et al., 2012) underscores the relevance of disinhibition, and existing treatments for this condition do not directly address this trait. Both emotion-based and relational conceptualizations of BPD provide explanations for disinhibited, impulsive behaviors (e.g., self-injurious actions, substance use, binge eating) that fit within the focus of their respective interventions. For example, although Linehan's (1993) biosocial theory of BPD was updated to include early expressions of trait impulsivity (Crowell et al., 2009), DBT focuses on rash actions in the context of strong emotions. By promoting more effective emotion regulation, DBT purportedly reduces reliance on impulsive behaviors that function to escape unwanted affective states. Relational approaches to BPD view impulsive behaviors as occurring in interpersonal contexts (Levy, 2005) and suggest that cultivating an increased ability to understand the motives of oneself and others (Bateman \& Fonagy, 2004) by repairing split-off object relations (Kernberg et al., 2008) reduces the urge to act on impulses. However, relegating impulsive behaviors to emotional and interpersonal contexts fails to account for mounting evidence that impulsivity in BPD may result from heritable neural profiles associated with impaired response inhibition (van Zutphen et al., 2015) that are independent from emotion-generating systems and early childhood experiences. 
Thus, a comprehensive treatment for BPD must include strategies to address trait impulsivity.

\section{Arguments for Personality-Based Treatment Recommendations for BPD}

One of the major advantages of personality-based approaches to psychopathology (e.g., the AMPD) is that they can provide a comprehensive, multidimensional assessment of the features underlying individual patients' symptoms. These dimensional personality profiles can be created for each patient and used by clinicians to craft personalized treatment plans targeting the specific mechanisms that maintain symptoms for that individual (Samuel \& Widiger, 2006). For example, AMPD's Criterion A level of personality dysfunction may be used as an overall severity metric to provide recommendations on the length or intensity of treatment. Additionally, if a patient endorses high levels of negative affectivity and disinhibition on Criterion B, treatment elements targeting these difficulties can be selected, while strategies targeting antagonism can be left out. Thus, assessing BPD with the AMPD can produce treatment plans that are comprehensive and efficient. Encouragingly, there is evidence that clinicians find that dimensional personality profiles are able to communicate important information, are easy to use, and are useful in treatment planning (Widiger \& Mullins-Sweatt, 2010).

Dimensional models of psychopathology are also useful for understanding co-occurring conditions. BPD is characterized by a high degree of comorbidity with other forms of psychopathology (Zanarini et al., 1998), with estimates as high as 75\% for lifetime cooccurrence with anxiety and depressive disorders (Grant et al., 2008) and 50\% for substance use disorders (Carpenter et al., 2015). People with BPD and comorbid conditions respond more poorly to non-BPD focused treatments than those without BPD (e.g., Vignarajah \& Links, 2009). However, rather than conceptualizing co-occurring disorders as discrete, categorical phenomena, comorbid conditions can be regarded as additional manifestations of shared underlying 
mechanisms (Brown \& Barlow, 2009). For example, in the HiTOP framework (Kotov et al., 2017), a patient with BPD, social anxiety disorder, depression, and alcohol use disorder can be conceptualized as displaying both internalizing and externalizing psychopathology. Thus, a personality-based dimensional approach to understanding psychopathology provides higherorder treatment targets that may simultaneously address comorbid conditions (Barlow et al., 2014; Sauer-Zavala, Southward, \& Semcho, 2020).

Despite the advantages of personality-based conceptions of psychopathology and treatment, these approaches are not currently well integrated in clinical practice. Several authors (e.g., Bach \& Presnall-Shvorin, 2020; Hopwood, 2018; Mullins-Sweatt et al., 2020) have articulated strategies for using personality profiles to select individualized treatment approaches; however, we contend that the substance of these recommendations may have resulted in unintended barriers. First, the majority of the treatment recommendations based on personality features involve matching existing interventions (e.g., interpersonal effectiveness in DBT) to particular traits (e.g., antagonism; Hopwood, 2018; Mullins-Sweatt et al., 2020). This approach requires that clinicians be trained in a variety of treatment protocols to provide comprehensive care, perhaps limiting uptake (McHugh et al., 2009). Additionally, treatment recommendations are often made at the facet level (Bach \& Presnall-Shvorin, 2020). In the Five Factor Model, each of the five broad domains of personality are composed of six facets, which would yield 30 distinct treatment approaches. Although this number of interventions is far fewer than the number of protocols required to address each DSM diagnosis, it may still result in significant therapist burden associated with learning a large number of treatments. Additionally, it is not clear that the facets organized beneath a broad personality domain are functionally distinct, warranting discrete treatment approaches. Thus, we argue that a single intervention to address 
the broad domain level of personality provides a balance between comprehensive coverage of transdiagnostic personality dimensions, while being practical for therapists to learn and implement.

\section{BPD Compass: A Customizable Treatment for BPD Based on Personality Profiles}

We (REDACTED) sought to create a treatment package for BPD that was informed by the substantive dimensions (Criteria A and B) of the AMPD. BPD Compass, which loosely stands for Cognitive-behavioral Modules for Personality Symptoms, was developed to 1) synthesize decades of research on mechanisms maintaining BPD into a comprehensive treatment, 2) address gaps left by existing interventions, and 3) be maximally efficient and disseminable. Incorporating assessment of Criterion A provides a metric of overall severity, perhaps allowing clinicians to estimate the number of BPD Compass sessions needed to address a given patient's symptoms (see section on Assessment and Personalization) or determine whether an alternative treatment approach is more appropriate. Assessment of Criterion B is used to determine which BPD Compass modules will be presented; discrete modules were developed to target negative affectivity, antagonism, and disinhibition using commonly applied treatment strategies: identification of values, techniques to promote cognitive flexibility, behavior change principles (alternative action, exposures), and mindfulness training. In the section below, we describe the theory that underscores our approach to targeting relevant dimensions of personality, summarize the skills and exercises included in BPD Compass, and highlight the treatment gaps this intervention addresses. Finally, we describe the strategies we used to increase the likelihood that BPD Compass will integrate well with routine practice settings.

\section{How Does BPD Compass Address Empirically Identified Mechanisms Maintaining BPD?}

We view the personality dimensions included in Criterion B of the AMPD as a 
framework to integrate decades of theoretical and empirical research on the nature of BPD. Indeed, BPD Compass was designed to engage the putative mechanisms associated with negative affectivity, antagonism, and disinhibition. We drew from emotion dysregulation (i.e., DBT, UP) and attachment insecurity (i.e., TFP, MBT, SFT) perspectives on treating BPD to specify the targets in the negative affectivity and antagonism modules, respectively, along with adding content specific to disinhibition. Thus, although we are not proposing a completely new conceptual framework for understanding this condition, BPD Compass' innovation lies in the way this intervention provides comprehensive coverage of the putative mechanisms maintaining BPD symptoms within a single intervention. In the section below, we briefly summarize the existing theory that underscores the modules included in our treatment. Additionally, when developing and testing a new treatment, it is important to confirm that the components included in each module indeed engage hypothesized mechanisms. Based on (Kazdin, 2007)'s criteria for determining whether a psychological process can serve as a mechanism of action, we have planned to collect empirical support to test the mechanistic relations between strategies and targets in BPD Compass; see the Research Agenda for BPD Compass section below).

Barlow and colleagues' functional model of neuroticism (Barlow, Ellard, et al., 2014; Barlow, Sauer-Zavala, et al., 2014) posits that aversive reactions to frequently occurring negative emotions prompt the use of emotionally avoidant coping strategies (e.g., self-injurious behaviors, binge eating, substance use) that paradoxically result in more frequent and intense negative emotions (i.e., exacerbating and maintaining negative affectivity; Bullis et al., 2019). By contrast, sustained decreases in the frequency of negative emotions, achieved by targeting aversive/avoidant responses to emotions, may constitute decreases in negative affectivity (for a description of what constitutes trait change, see Magidson et al., 2014). Transdiagnostic 
behavioral interventions targeting aversive reactivity have been associated with significantly larger decreases in neuroticism than symptom-focused protocols (Sauer-Zavala, Fournier, et al., 2020) and improvements in negative affectivity in transdiagnostic treatments may even predict symptom reduction (Stumpp et al., in preparation).

Antagonism, characterized by distrust, manipulativeness, and oppositionality (MullinsSweatt et al., 2012), is associated with strained interpersonal relationships and is a risk factor for developing externalizing psychopathology (Anderson et al., 2007; Kotov et al., 2010; Miller et al., 2003). Higher levels of antagonism are associated with insecure attachments to childhood caregivers, which can manifest in adulthood as behaviors that function to protect a person in interpersonal contexts perceived as threatening (Young et al., 2006). Here, attachment insecurity represents an actionable functional mechanism linking the personality trait of antagonism to externalizing symptoms, akin to the role of aversive reactivity in the relation between neuroticism and negative emotions. Emerging research suggests that improving patients' ability to consider others' perspectives, along with challenging negative schemas about oneself and others, improves attachment security in adults (Levy et al., 2006; Vogt \& Norman, 2019).

Finally, disinhibition, or trait impulsivity, is characterized by sensation-seeking (the tendency to seek out novel and thrilling experiences), lack of deliberation (the tendency to act without thinking), lack of persistence (an inability to remain focused on a task), and urgency (the tendency to act rashly in response to positive and negative emotional experiences; Cyders et al., 2007; Whiteside et al., 2005). Roberts and colleagues have published several theoretical accounts of how to alter this trait in treatment (Magidson et al., 2014; Roberts et al., 2017). They suggest that individuals' expectancies about their performance on certain tasks, along with how much they value these actions, predict conscientious behaviors (e.g., paying bills on time, subjugating 
impulses that would be gratifying in the short-term; Eccles, 2009). Others have suggested that trait impulsivity is maintained by high reward orientation such that disinhibited individuals will continue to pursue rewards (e.g., relief from negative emotions, substance-related highs) despite negative consequences (Carver \& White, 1994; Gray, 1987). Thus, intervention strategies that focus on values, provide immediate (reinforcing) feedback on progress, and engage performance expectancies may be particularly useful for this trait (Magidson et al., 2014).

\section{What Skills/Activities Are Included in BPD Compass?}

BPD Compass consists of four skill domains applied to the core personality-based mechanisms described above (i.e., negative affectivity, antagonism, disinhibition; Table 1). These domains include values identification, skills for thinking (i.e., cognitive flexibility), skills for doing (i.e., alternative actions, exposure), and skills for being (i.e., mindfulness training). What makes our treatment different from the typical provision of these skills is the explicit focus on emotion tolerance, trust, and delay of impulsive gratification.

Introduction and case conceptualization. The initial session is focused on psychoeducation about BPD and an overview of treatment content. The therapist first reviews symptoms of BPD and any other conditions the patient is experiencing and then describes how these difficulties can be explained by three risk factors: attempts to push away frequent strong negative emotions, difficulty trusting others, and difficulty resisting the urges to act impulsively. Patients are asked to reflect on how these three issues manifest in their own lives and the therapist explains that treatment will focus on helping them 1) tolerate emotions, 2) test the extent to which they can trust others in their lives, and 3) delay acting on urges in order to live in accordance with long-term goals. The major theme across all modules/skills is that patients often pursue short-term relief (escape from emotions, engaging in protective relationship behaviors, 
engaging in satisfying impulsive actions) that limits their ability to live in line with their values. This conceptualization is described in the first session and is brought up explicitly in subsequent sessions.

Identifying and Approaching Values. Next, patients spend at least two sessions identifying their values and considering the extent to which they are currently living in accordance with them. To identify personal values, patients are provided with a list of domains (e.g., family, career, spirituality) and asked to answer prompting questions (e.g., what does this domain mean to you, what qualities do you want to embody in this domain). These procedures were inspired by acceptance and commitment therapy (Hayes et al., 1999) and values-based behavioral activation (Hopko et al., 2003). In BPD Compass, values identification is conducted at the beginning of treatment to foster the therapist's understanding of the patient beyond their symptoms and create a standard against which to evaluate the patient's behaviors (e.g., "is this action in line with your values?") to motivate change. Specifically, patients are encouraged to consider both the short- and long-term effects of their behaviors to reflect on whether they are moving closer to their values. Although values identification may involve negative affectivity, antagonism, and disinhibition, values-focused work is particularly in line with Magidson's et al. (2014) recommendations for targeting disinhibition.

Skills for Thinking. Using patients' values as guiding principles, the cognitive skills in BPD Compass are designed to help patients practice flexible thinking around emotion-provoking situations, maladaptive schemas about relationships, and beliefs about their inability to resist impulsive urges. At its core, cognitive flexibility involves identifying overly negative, biased, or ineffective thoughts and considering alternative interpretations to better evaluate the evidence for these thoughts (Beck et al., 1987). Patients use a standard thought record form throughout these 
sessions to assist in the examination of their thoughts, which are subjected to challenging questions as a means to generate alternative perspectives. To address intolerance of emotions, specifically, patients are encouraged to generate alternative appraisals for thoughts about emotions themselves (e.g., "I always overreact" becomes "given my previous experiences in similar situations, it makes sense my gut reaction would be strong”).

BPD Compass also incorporates two supplemental activities to address unhelpful thinking patterns in relationships and in response to triggers for impulsive actions. With regard to thoughts about relationships, patients are asked to examine multiple dimensions of trust (e.g., paying back a debt, taking care of a child) for significant others in their lives. Drawn from cognitive processing therapy (Resick et al., 2016), this technique is designed to challenge all-ornothing thinking regarding the trustworthiness of other people by asking patients to evaluate the degree to which they trust each person in their life on each dimension. For thoughts about impulses, BPD Compass patients are asked to explore the functional origin of their impulsive urges and related thoughts. For example, the functional origin of sensation-seeking urges may be the thought that "nothing feels as good as the rush I get from sex." Finally, patients can have an optional overview/wrap-up session to either troubleshoot particularly difficult thoughts or practice identifying and challenging core beliefs that the patient or therapist may have noticed throughout the prior cognitive-focused sessions.

Skills for Doing. BPD Compass incorporates common principles of behavior change by encouraging patients first to identify unhelpful emotional, relationship, and impulsive actions and then practice behaviors that bring patients closer to their values. Patients are first oriented to the negative reinforcement cycle of unhelpful behaviors (Barlow, 2002). For example, although self-injuring during an altercation with a loved one may satisfy the urge to reduce intense 
emotions, it prevents patients from learning that emotions and urges can be tolerated and may also lead to poor health and relationship outcomes. Skills for Doing are designed to break the cycle of negative reinforcement and facilitate 1) an approach-oriented stance towards experiencing emotions, 2) a willingness to feel vulnerable and build trust in relationships, and 3) an ability to resist immediately responding to urges. The two primary behavioral strategies used are alternative action and exposure. Alternative action refers to replacing a current unhelpful behavior with a more adaptive one, whereas exposures are used when a patient avoids situations that may elicit strong emotions or urges. Continuing with the example above, a patient may practice speaking calmly and actively listening when communicating (i.e., alternative action) or initiating a difficult conversation (i.e., exposure) with a loved one, rather than engaging in selfinjury. Patients use a tracking form to identify unhelpful emotional, relationship, and impulsive behaviors and plan specific alternative actions and exposure ideas to practice between sessions.

Skills for Being. BPD Compass also includes mindfulness training to cultivate presentfocused, non-judgmental attention. Patients practice nonjudgmentally observing the thoughts, physical sensations, and behavioral urges that arise in response to emotion-provoking situations, interpersonal conflicts, and triggers for impulsive actions. This is accomplished via three formal meditation exercises focused on each BPD-relevant personality dimension. The meditation focused on emotions is adapted from Mindfulness Based Cognitive Therapy (Segal et al., 2013) and encourages patients to observe the internal experiences that arise naturally, whereas the relationship-focused and urge-focused meditations ask patients to bring to mind a recent conflict or triggering stimulus (e.g., a party, a specific substance). Beyond the formal meditation, patients practice and track their nonjudgmental, present-moment attention in real-time situations. Finally, an optional session may be used to deepen or troubleshoot patients' practice with mindfulness. 
Assessment and Personalization. The delivery of BPD Compass can be personalized based on information provided by Criteria A and B of the AMPD. Criterion A can be assessed with the Level of Personality Function Scale Brief 2.0 (LPFS; Weekers et al., 2019), which provides an overall severity rating of a patient's self and relationship dysfunction. It may be possible to use this information to personalize the length of treatment with BPD Compass required to observe symptom remission or to determine if a more intensive or focused intervention is necessary. Empirical data is needed to determine if the LPFS can be used in this manner (see our Research Agenda for BPD Compass Section for more information).

Additionally, given that the dimensions included Criterion B are closely related to the FFM, a well-established personality paradigm, a range of psychometrically-sound assessment tools can be applied (Sleep et al., 2021). For instance, measures assessing the range of normal personality (NEO Personality Inventory-3; McCrae et al., 2005; International Personality Item Pool; Donnellan et al., 2006; Maples et al., 2014; Big Five Inventory-2 [BFI-2]; Soto \& John, 2017) range in length from 10 to 300 items, allowing researchers/clinicians to choose the level of specificity for their assessment. However, some authors have speculated that measures of normal personality do not capture the full range of functioning for those with personality disorders (Krueger et al., 2012) and created FFM-based instruments for BPD. The Five-Factor Borderline Inventory (Mullins-Sweatt et al., 2012) and its short form (DeShong et al., 2016) provide coverage of maladaptive variants of neuroticism, agreeableness, and conscientiousness. Finally, although not BPD-specific, the Personality Inventory for DSM-5 (Krueger et al., 2012) also captures more extreme presentations of the FFM relevant to personality disorders.

Thus, there is a wide pool of instruments that can be used to assess and personalize BPD Compass. These instruments can generate personality profiles to identify relative areas of 
elevation (i.e., high antagonism relative to scores on other FFM domains), as well as absolute elevations (i.e., high antagonism compared to normative data). These data can then be used to select relevant modules from BPD Compass. BPD Compass was developed to be fully modular so that skills addressing neuroticism, antagonism, or disinhibition could be presented in isolation or in any order to prioritize areas of greatest need. If a patient exhibits elevations on all three domains targeted by BPD Compass, we recommend providing 16-18 sessions (Table 1). However, if a patient only displays clinically relevant elevations in one domain, fewer session may be needed.

For an example of FFM profiles using the BFI-2 from our current trial evaluating the efficacy of BPD Compass in a sample of individuals meeting DSM-5 criteria for BPD, see Figure 1. Case A displays high neuroticism and average levels of agreeableness and consciousness, suggesting treatment might prioritize skills for addressing aversive reactions to emotions. Case B and Case $\mathrm{C}$ demonstrate high neuroticism along with deficits in one additional personality dimension, conscientiousness and agreeableness, respectively. Finally, Case D exhibits high neuroticism, low agreeableness, and low conscientiousness, suggesting the comprehensive approach taken by BPD Compass would be warranted. Although it is currently unknown which personality measures provide the most predictive utility for selecting BPD Compass modules or whether facet-level scores provide important information beyond domainlevel scores for personalizing treatment, we are currently collecting data to address these questions (see Research Agenda section below).

How Does BPD Compass Address Gaps in the Existing Treatment Options for BPD?

BPD Compass was developed to address patient and provider-level gaps in the current treatment offerings for BPD. We view BPD Compass as a complement to existing evidence- 
based treatments for this condition. Given that BPD is relatively common in outpatient samples and many patients with BPD display less severe symptoms (Goldberg, 2001), we contend that many patients with BPD may not require the longer-term, more intensive treatments that have amassed the most research support to date. Thus, BPD Compass was explicitly developed to be relatively short-term, delivered in its entirety in 16-18 weekly sessions (i.e., 4-5 months). Directing patients with less severe symptoms to shorter-term interventions delivered by generalist providers may free up space on specialist caseloads for those that truly need this level of care (see Laporte et al., 2018 for evidence on using stepped care approaches in treatment for BPD). Moreover, because BPD Compass is composed of well-known therapeutic strategies (i.e., cognitive flexibility, behavior change/exposure, mindfulness training) that are frequently trained in graduate programs, we believe this approach can be easily integrated into routine practice. In our current trial evaluating the efficacy of BPD Compass, most study therapists are graduate students with less than one year of clinical experience who have generally been able to competently deliver the intervention.

Despite the intended brief duration of BPD Compass, we also view this intervention as a comprehensive package that addresses the core personality-based mechanisms implicated in the development and maintenance of BPD. Instead of primarily focusing on emotion dysregulation or attachment insecurity, BPD Compass contains skills to address neuroticism, antagonism, and trait impulsivity (disinhibition). Additionally, BPD Compass is the first treatment to our knowledge for this condition that was explicitly designed to be customizable based on the mechanistic factors maintaining each patient's symptoms. As described previously, existing FFM questionnaires can be used to determine the personality dimensions that characterize individual patients and corresponding BPD Compass modules can be applied. 


\section{How Was BPD Compass Developed to be Disseminable?}

Many people with BPD may have particularly pronounced difficulties accessing care (Lawn \& McMahon, 2015). For example, in the United Kingdom, BPD has only recently been considered a diagnosis that mental health providers are responsible to treat (NICE, 2009). When care is available, people with BPD may experience substantial stigma from providers (Rogers \& Acton, 2012), many of whom refuse to treat patients with BPD (Sulzer, 2015). Unfortunately, access to specialist providers with the expertise and inclination to treat BPD is limited (Iliakis et al., 2019), and many patients lack the financial resources to afford gold-standard, intensive care (Tomko et al., 2014).

Given these barriers to accessing mental healthcare, we contend that any new treatment must consider dissemination issues during development. Our goal was to create an intervention that 1) could be applied in generalist mental healthcare settings and 2) would be relatively easy to train across various professions (e.g., social workers, licensed mental health counselors, psychologists, psychiatrists). Although we fully acknowledge that severe forms of BPD require intensive specialist treatments such as DBT, TFP, SFT, or MBT, there is evidence that usual care is still quite beneficial (Finch et al., 2019) when individuals with this condition can actually receive it. Thus, we designed BPD Compass to be delivered in weekly, 50-minute outpatient sessions in line with typical service delivery models. Additionally, both patient-level factors (e.g., difficulty affording treatment; Tomko et al., 2014) and system-level factors (e.g., long waitlists) underscore the need for efficient, yet flexible treatments (Southward et al., 2020). Although a full course of BPD Compass lasts 16-18 sessions, it could be completed in as few as 9 sessions for patients with dysfunction in only one personality dimension (though it is an empirical question whether this brief of treatment would be sufficient). This flexibility makes 
BPD Compass ideally suited to a stepped care approach to BPD (Laporte et al., 2018).

Another important consideration for maximizing widespread dissemination of an intervention is the burden placed on clinicians to deliver it. BPD Compass is a manualized cognitive-behavioral treatment (CBT) with a patient workbook (REDACTED, 2020) and therapist guide (REDACTED, in preparation). By providing clear guidance on the application of this treatment for clinicians in a familiar format (i.e., workbook chapters corresponding to session-by-session material), any mental health provider that is inclined to work through BPD Compass with their patients will be able to more quickly learn and apply it. Although we do offer consultation/training services, we explicitly view these offerings as enriching one's practice, rather than necessary to provide the treatment. Finally, we elected to use a cognitive-behavioral approach given that CBT is reported as the primary theoretical orientation by most providers in typical mental health service settings (Wolitzky-Taylor et al., 2019) and most training programs for clinical psychology focus on developing student competencies in delivering CBT (Heatherington et al., 2012). Although we believe that adopting a manualized, CBT approach increases the disseminablility of BPD Compass, it is important to note that the eclectic use of other theoretical orientations is not precluded; indeed, psychodynamic or interpersonal techniques that use the patient's relationship with their therapist as a vehicle for new learning can be integrated within structured CBT exercises (Westen, 2000). Overall, by making it clear that BPD can be successfully treated in generalist settings, stigma associated with this condition may be diminished.

\section{What is Our Research Agenda for BPD Compass?}

We are currently evaluating the efficacy for BPD Compass with an RCT in which patients are assigned to receive this treatment immediately upon enrollment in the study or 
following an 18-week delay (clinicaltrials.gov registration: REDACTED); all study procedures are approved by our local institutional review board. This design allows us to compare BPD Compass to waitlist; however, because all participants eventually receive the intervention, we will collapse the immediate and delayed treatment conditions to increase our power for withingroup analyses. Given that this study represents the first evaluation of this novel intervention, we elected to deliver all skills/mechanistic modules to all participants rather than personalizing delivery based on pre-treatment assessment.

To date, we have enrolled 37 patients (14 assigned to immediate treatment and 15 assigned to delayed treatment) out of our projected $N$ of 50 individuals. Patients are included if they meet DSM-5 criteria for BPD (assessed via clinician administration of the Structured Clinical Interview for DSM-5 Personality Disorders; First et al., 1997), agree to refrain from concurrent behavioral treatment, and agree to remain on a stable dose of psychotropic medication. Exclusion criteria are based solely on the well-being of participants and include difficulties that would warrant the prioritization of alternative care: 1) uncontrolled bipolar I disorder or psychotic/delusional symptoms (i.e., a manic episode or delusions/hallucinations in the past 12 months), 2) acute suicidal intent requiring immediate hospitalization, and 3) an untreated substance use disorder that would be better addressed with supervised detoxification and or medication management. Of note, our recruitment materials did not mention acute suicidal intent as a rule out. Of the 59 individuals that completed a study intake, none were excluded for acute suicidality, although many endorsed ideation. This sample composition is in line with epidemiological data suggesting that $80-97 \%$ of individuals with BPD are not actively suicidal (i.e., did not attempt suicide in the past year; Grilo \& Udo, 2021; Yen et al., 2021), underscoring the need for treatments focused on less-severe individuals. 
Given that there have been several theoretical accounts of how to directly treat the personality-based domains included in dimensional models of psychopathology (AMPD, HiTOP; e.g., Bach \& Presnall-Shvorin, 2020; Hopwood, 2018; Mullins-Sweatt et al., 2020), we wanted to include preliminary efficacy data to demonstrate the utility of a personality-based approach to BPD. Nine patients assigned have completed a full course of care with BPD Compass. Outcome data for each individual can be viewed in Table 2. Six of nine patients demonstrated statistically significant improvements in BPD symptoms and depressive symptoms, and six of nine patients demonstrated change in anxiety symptoms in the expected direction. This initial review of patient improvement on our trial is consistent with novel treatment development recommendations (Barlow et al., 2008). If the first cases treated with a newly developed intervention do not demonstrate the anticipated effect, treatment can be refined before substantial resources are used for a large-scale trial. The pattern of results demonstrated by the first nine BPD Compass treatment completers suggests that this intervention has promise as a short-term intervention for BPD and commonly co-occurring symptoms (i.e., anxiety and depression).

Given that BPD Compass was developed to address personality dimensions related to BPD, we also plan to examine whether these dimensions and their putative mechanistic processes (i.e., aversive reactivity to emotions, attachment insecurity, goal-pursuit expectancies), change over the course of treatment. Kazdin (2007) has proposed five criteria for determining whether a psychological process can serve as a mechanism of change: 1) finding a strong association between the mechanism of action and the outcome, 2) establishing temporal precedence where change in the mechanism of action precedes changes in the outcome, 3 ) manipulating the levels of the mechanisms to determine how they relate to outcomes; 4) identifying a dose-response relationship where greater change in a mechanism of action leads to 
better outcomes, and 5) replicating findings. The design of our trial will allow us to test Kazdin's first, second, and fourth criteria. Specifically, we are conducting weekly repeated measurement of BPD symptoms, relevant personality domains, and intermediary mechanisms.

Finally, because we are currently testing BPD Compass in its entirety, we will be unable to determine whether skills associated with a particular personality domain uniquely engage their intended target. Thus, our immediate next step will be to conduct a component analyses of BPD Compass in which skills associated with each higher-order personality trait will be presented in isolation to determine if they result in improvement on these dimensions. Additionally, given that the delivery of BPD Compass modules can be personalized, it will also be important to compare trajectories of improvement across patients who receive tailored modules of BPD Compass versus those who are treated with the standard, full protocol. Another area for future research is to determine whether the AMPD's Criterion A can be used to predict a dose response to BPD Compass or whether it can indicate whether a more intensive treatment is warranted.

Conclusions. The purpose of this manuscript is to provide the conceptual background for a novel, short-term intervention for BPD that maps on to Criteria A and B of the AMPD. BPD Compass was developed to incorporate recent research on dimensional models of personality pathology into a comprehensive, yet customizable, treatment protocol. This intervention includes components to address negative affectivity, antagonism, and disinhibition, and was conceived to be fully modular such that pre-treatment personality profiles can be used to personalize the selection of modules presented. BPD Compass was developed explicitly as a short-term option for addressing BPD that can complement existing, higher-intensity interventions. Preliminary patient data suggests that BPD Compass is a promising approach to addressing BPD and commonly co-occurring conditions, warranting continued empirical study. 


\section{References}

Agrawal, H. R., Gunderson, J., Holmes, B. M., \& Lyons-Ruth, K. (2004). Attachment Studies with Borderline Patients: A Review. Harvard Review of Psychiatry, 12(2), 94-104. https://doi.org/10.1080/10673220490447218

American Psychiatric Association. (2013). Diagnostic and statistical manual of mental disorders (5th ed.). Author.

Anderson, K. G., Tapert, S. F., Moadab, I., Crowley, T. J., \& Brown, S. A. (2007). Personality risk profile for conduct disorder and substance use disorders in youth. Addictive Behaviors, 32(10), 2377-2382. https://doi.org/10.1016/j.addbeh.2007.02.006

Andrews, G. (1996). Comorbidity and the general neurotic syndrome. The British Journal of Psychiatry, 30, 76-84.

Au, T. M., Sauer-Zavala, S., King, M. W., Petrocchi, N., Barlow, D. H., \& Litz, B. T. (2017). Compassion-based therapy for trauma-related shame and posttraumatic stress: Initial evaluation using a multiple baseline design. Behavior Therapy, 48(2), 207-221. https://doi.org/10.1016/j.beth.2016.11.012

Bach, B., \& Presnall-Shvorin, J. (2020). Using DSM-5 and ICD-11 personality traits in clinical treatment. In C. W. Lejuez \& K. L. Gratz (Eds.), Handbook of Personality Disorders. Cambridge University Press.

Barlow, D. H., Ellard, K. K., Sauer-Zavala, S., Bullis, J. R., \& Carl, J. R. (2014). The Origins of Neuroticism. Perspectives on Psychological Science: A Journal of the Association for Psychological Science, 9(5), 481-496. https://doi.org/10.1177/1745691614544528

Barlow, D. H., Nock, M. K., \& Hersen, M. (2008). Single Case Experimental Designs: Strategies for Studying Behavior Change (3rd edition). Pearson. 
Barlow, D. H., Sauer-Zavala, S., Carl, J. R., Bullis, J. R., \& Ellard, K. K. (2014). The nature, diagnosis, and treatment of neuroticism: Back to the future. Clinical Psychological Science, 2(3), 344-365. https://doi.org/10.1177/2167702613505532

Bateman, A. W., \& Fonagy, P. (2004). Mentalization-Based Treatment of BPD. Journal of Personality Disorders, 18(1), 36-51. https://doi.org/10.1521/pedi.18.1.36.32772

Bentley, K. H., Gallagher, M. W., Carl, J. R., \& Barlow, D. H. (2014). Development and validation of the Overall Depression Severity and Impairment Scale. Psychological Assessment, 26(3), 815-830. https://doi.org/10.1037/a0036216

Black, D. W., Blum, N., Pfohl, B., \& St. John, D. (2004). The STEPPS Group Treatment Program for Outpatients with Borderline Personality Disorder. Journal of Contemporary Psychotherapy, 34(3), 193-210. https://doi.org/10.1023/B:JOCP.0000036630.25741.83

Bowlby, J. (1973). Attachment and loss (Vol. 2). Basic Books.

Brown, T. A. (2007). Temporal course and structural relationships among dimensions of temperament and DSM-IV anxiety and mood disorder constructs. Journal of Abnormal Psychology, 116(2), 313-328. https://doi.org/10.1037/0021-843X.116.2.313

Brown, T. A., \& Barlow, D. H. (2009). A proposal for a dimensional classification system based on the shared features of the DSM-IV anxiety and mood disorders: Implications for assessment and treatment. Psychological Assessment, 21(3), 256.

Bullis, J. R., Boettcher, H. T., Sauer-Zavala, S., Farchione, T. J., \& Barlow, D. H. (2019). What is an emotional disorder? A transdiagnostic mechanistic definition with implications for assessment, treatment, and prevention. Clinical Psychology: Science and Practice.

Carpenter, R. W., Wood, P. K., \& Trull, T. J. (2015). Comorbidity of borderline personality disorder and lifetime substance use disorders in a nationally representative sample. 
Journal of Personality Disorders, 30(3), 336-350.

https://doi.org/10.1521/pedi_2015_29_197

Carver, C. S. (1997). Adult attachment and personality: Converging evidence and a new measure. Personality and Social Psychology Bulletin, 23(8), 865-883. https://doi.org/10.1177/0146167297238007

Carver, C. S., \& White, T. L. (1994). Behavioral inhibition, behavioral activation, and affective responses to impending reward and punishment: The BIS/BAS Scales. Journal of Personality and Social Psychology, 67(2), 319.

Chartonas, D., Kyratsous, M., Dracass, S., Lee, T., \& Bhui, K. (2017). Personality disorder: Still the patients psychiatrists dislike? BJPsych Bulletin, 41(1), 12-17. https://doi.org/10.1192/pb.bp.115.052456

Clarkin, J. F., Foelsch, P. A., Levy, K. N., Hull, J. W., Delaney, J. C., \& Kernberg, O. F. (2001). The development of a psychodynamic treatment for patients with borderline personality disorder: A preliminary study of behavioral change. Journal of Personality Disorders, $15(6), 487-495$.

Costa, P. T., \& McCrae, R. R. (1990). Personality disorders and the five-factor model of personality. Journal of Personality Disorders, 4(4), 362-371. https://doi.org/10.1521/pedi.1990.4.4.362

Crittenden, P., \& Ainsworth, D. (1989). Child maltreatment and attachment theory. In D. Cicchetti \& V. Carlson (Eds.), Child Maltreatment: Theory and Research on the Causes and Consequences of Child Abuse and Neglect (pp. 432-463). Cambridge University Press.

Crowell, S. E., Beauchaine, T. P., \& Linehan, M. M. (2009). A biosocial developmental model 
of borderline personality: Elaborating and extending Linehan's theory. Psychological Bulletin, 135(3), 495-510. https://doi.org/10.1037/a0015616

Cyders, M. A., Smith, G. T., Spillane, N. S., Fischer, S., Annus, A. M., \& Peterson, C. (2007). Integration of impulsivity and positive mood to predict risky behavior: Development and validation of a measure of positive urgency. Psychological Assessment, 19(1), 107-118. https://doi.org/10.1037/1040-3590.19.1.107

DeShong, H. L., Mullins-Sweatt, S. N., Miller, J. D., Widiger, T. A., \& Lynam, D. R. (2016). Development of a short form of the Five-Factor Borderline Inventory. Assessment, 23(3), 342-352. https://doi.org/10.1177/1073191115581475

Ef, F., Ea, I., Sr, M., \& Lw, C.-K. (2019). A meta-analysis of treatment as usual for borderline personality disorder. Personality Disorders, 10(6), 491-499. https://doi.org/10.1037/per0000353

Fallon, P. (2003). Travelling through the system: The lived experience of people with borderline personality disorder in contact with psychiatric services. Journal of Psychiatric and Mental Health Nursing, 10(4), 393-401. https://doi.org/10.1046/j.13652850.2003.00617.x

First, M. B., Gibbon, M., Spitzer, R. L., Williams, J. B., \& Benjamin, L. S. (1997). Structured Clinical Interview for DSM-IV Axis II Personality Disorders. American Psychiatric Press.

Giesen-Bloo, J., van Dyck, R., Spinhoven, P., van Tilburg, W., Dirksen, C., van Asselt, T., Kremers, I., Nadort, M., \& Arntz, A. (2006). Outpatient psychotherapy for borderline personality disorder: Randomized trial of Schema-Focused Therapy vs TransferenceFocused Psychotherapy. Archives of General Psychiatry, 63(6), 649-658. https://doi.org/10.1001/archpsyc.63.6.649 
Gray, J. A. (1987). Perspectives on anxiety and impulsivity: A commentary. Journal of Research in Personality, 21(4), 493-509. https://doi.org/10.1016/0092-6566(87)90036-5

Grilo, C. M., \& Udo, T. (2021). Association of Borderline Personality Disorder Criteria With Suicide Attempts Among US Adults. JAMA network open, 4(5), e219389. https://doi.org/10.1001/jamanetworkopen.2021.9389

Gunderson, J., Masland, S., \& Choi-Kain, L. (2018). Good psychiatric management: A review. Current Opinion in Psychology, 21, 127-131. https://doi.org/10.1016/j.copsyc.2017.12.006

Hayes, S., Strosahl, K., \& Wilson, K. (1999). Acceptance and commitment therapy: Understanding and treating human suffering. Guilford Press.

Heatherington, L., Messer, S. B., Angus, L., Strauman, T. J., Friedlander, M. L., \& Kolden, G. G. (2012). The Narrowing of Theoretical Orientations in Clinical Psychology Doctoral Training. Clinical Psychology: Science and Practice, 19(4), 364-374. https://doi.org/10.1111/cpsp.12012

Hopko, D. R., Lejuez, C. W., Ruggiero, K. J., \& Eifert, G. H. (2003). Contemporary behavioral activation treatments for depression: Procedures, principles, and progress. Clinical Psychology Review, 23(5), 699-717. https://doi.org/10.1016/S0272-7358(03)00070-9

Hopwood, C. J. (2018). A framework for treating DSM-5 alternative model for personality disorder features. Personality and Mental Health, 12(2), 107-125. https://doi.org/10.1002/pmh.1414

Iliakis, E. A., Sonley, A. K. I., Ilagan, G. S., \& Choi-Kain, L. W. (2019). Treatment of borderline personality disorder: Is supply adequate to meet public health needs? Psychiatric Services, 70(9), 772-781. https://doi.org/10.1176/appi.ps.201900073 
Jacobson, N. S., \& Truax, P. (1991). Clinical significance: A statistical approach to defining meaningful change in psychotherapy research. Journal of Consulting and Clinical Psychology, 59(1), 12-19.

Joyce, P. R., Mulder, R. T., Luty, S. E., McKenzie, J. M., Sullivan, P. F., \& Cloninger, R. C. (2003). Borderline personality disorder in major depression: Symptomatology, temperament, character, differential drug response, and 6-month outcome. Comprehensive Psychiatry, 44(1), 35-43. https://doi.org/10.1053/comp.2003.50001

Kazdin, A. E. (2007). Mediators and mechanisms of change in psychotherapy research. Annual Review of Clinical Psychology, 3(1), 1-27. https://doi.org/10.1146/annurev.clinpsy.3.022806.091432

Kernberg, O. F. (1975). Borderline conditions and pathological narcissism. Aronson. Kernberg, O. F. (1984). Severe personality disorders: Psychotherapeutic strategies. Yale University Press.

Kernberg, O. F., Yeomans, F. E., Clarkin, J. F., \& Levy, K. N. (2008). Transference focused psychotherapy: Overview and update. The International Journal of Psychoanalysis, 89(3), 601-620. https://doi.org/10.1111/j.1745-8315.2008.00046.x

Kliem, S., Kröger, C., \& Kosfelder, J. (2010). Dialectical behavior therapy for borderline personality disorder: A meta-analysis using mixed-effects modeling. Journal of Consulting and Clinical Psychology, 78(6), 936-951. https://doi.org/10.1037/a0021015

Kotov, R., Gamez, W., Schmidt, F., \& Watson, D. (2010). Linking “big” personality traits to anxiety, depressive, and substance use disorders: A meta-analysis. Psychological Bulletin, 136(5), 768-821. https://doi.org/10.1037/a0020327

Kotov, R., Krueger, R. F., Watson, D., Achenbach, T. M., Althoff, R. R., Bagby, R. M., Brown, 
T. A., Carpenter, W. T., Caspi, A., Clark, L. A., Eaton, N. R., Forbes, M. K., Forbush, K. T., Goldberg, D., Hasin, D., Hyman, S. E., Ivanova, M. Y., Lynam, D. R., Markon, K., ... Zimmerman, M. (2017). The Hierarchical Taxonomy of Psychopathology (HiTOP): A dimensional alternative to traditional nosologies. Journal of Abnormal Psychology, 126(4), 454-477. https://doi.org/10.1037/abn0000258

Krueger, R. F., Derringer, J., Markon, K. E., Watson, D., \& Skodol, A. E. (2012). Initial construction of a maladaptive personality trait model and inventory for DSM-5. Psychological Medicine, 42(9), 1879-1890. https://doi.org/10.1017/S0033291711002674

Laporte, L., Paris, J., Bergevin, T., Fraser, R., \& Cardin, J.-F. (2018). Clinical outcomes of a stepped care program for borderline personality disorder. Personality and Mental Health, 12(3), 252-264. https://doi.org/10.1002/pmh.1421

Lawn, S., \& McMahon, J. (2015). Experiences of care by Australians with a diagnosis of borderline personality disorder. Journal of Psychiatric and Mental Health Nursing, 22(7), 510-521. https://doi.org/10.1111/jpm.12226

Levy, K. N. (2005). The implications of attachment theory and research for understanding borderline personality disorder. Development and Psychopathology, 17(4), 959-986. https://doi.org/10.1017/S0954579405050455

Levy, K. N., Meehan, K. B., Kelly, K. M., Reynoso, J. S., Weber, M., Clarkin, J. F., \& Kernberg, O. F. (2006). Change in attachment patterns and reflective function in a randomized control trial of transference-focused psychotherapy for borderline personality disorder. Journal of Consulting and Clinical Psychology, 74(6), 1027-1040. https://doi.org/10.1037/0022-006X.74.6.1027

Linehan, M. (1993). Cognitive-behavioral Treatment of Borderline Personality Disorder. 


\section{Guilford Press.}

Linehan, M. M. (2015). DBT skills training manual (2nd edition). The Guildford Press.

Lohman, M. C., Whiteman, K. L., Yeomans, F. E., Cherico, S. A., \& Christ, W. R. (2016).

Qualitative analysis of resources and barriers related to treatment of borderline personality disorder in the United States. Psychiatric Services, 68(2), 167-172. https://doi.org/10.1176/appi.ps.201600108

Magidson, J. F., Roberts, B., Collado-Rodriguez, A., \& Lejuez, C. W. (2014). Theory-driven intervention for changing personality: Expectancy value theory, behavioral activation, and conscientiousness. Developmental Psychology, 50(5), 1442-1450. https://doi.org/10.1037/a0030583

McHugh, R. K., Murray, H. W., \& Barlow, D. H. (2009). Balancing fidelity and adaptation in the dissemination of empirically-supported treatments: The promise of transdiagnostic interventions. Behaviour Research and Therapy, 47(11), 946-953. https://doi.org/10.1016/j.brat.2009.07.005

Miller, J. D., Lynam, D., \& Leukefeld, C. (2003). Examining antisocial behavior through the lens of the five factor model of personality. Aggressive Behavior, 29(6), 497-514. https://doi.org/10.1002/ab.10064

Mullins-Sweatt, S. N., Edmundson, M., Sauer-Zavala, S., Lynam, D. R., Miller, J. D., \& Widiger, T. A. (2012). Five-Factor Measure of Borderline Personality Traits. Journal of Personality Assessment, 94(5), 475-487. https://doi.org/10.1080/00223891.2012.672504

Mullins-Sweatt, S. N., Hopwood, C. J., Chmielewski, M., Meyer, N. A., Min, J., Helle, A. C., \& Walgren, M. D. (2020). Treatment of personality pathology through the lens of the hierarchical taxonomy of psychopathology: Developing a research agenda. Personality 
and Mental Health, 14(1), 123-141. https://doi.org/10.1002/pmh.1464

Norman, S. B., Hami Cissell, S., Means-Christensen, A. J., \& Stein, M. B. (2006). Development and validation of an Overall Anxiety Severity And Impairment Scale (OASIS). Depression and Anxiety, 23(4), 245-249. https://doi.org/10.1002/da.20182

Ozkan, M., \& Altindag, A. (2005). Comorbid personality disorders in subjects with panic disorder: Do personality disorders increase clinical severity? Comprehensive Psychiatry, 46(1), 20-26. https://doi.org/10.1016/j.comppsych.2004.07.015

Roberts, B. W., Hill, P. L., \& Davis, J. P. (2017). How to change conscientiousness: The sociogenomic trait intervention model. Personality Disorders: Theory, Research, and Treatment, 8(3), 199-205. https://doi.org/10.1037/per0000242

Rogers, B., \& Acton, T. (2012). 'I think we're all guinea pigs really': A qualitative study of medication and borderline personality disorder. Journal of Psychiatric and Mental Health Nursing, 19(4), 341-347. https://doi.org/10.1111/j.1365-2850.2011.01800.x

Samuel, D. B., \& Widiger, T. A. (2006). Clinicians' judgments of clinical utility: A comparison of the DSM-IV and five-factor models. Journal of Abnormal Psychology, 115(2), 298308. https://doi.org/10.1037/0021-843X.115.2.298

Sansone, R. A. (2004). Chronic suicidality and borderline personality. Journal of Personality Disorders, 18(3), 215-225. https://doi.org/10.1521/pedi.18.3.215.35444

Sauer-Zavala, S., Bentley, K. H., \& Wilner, J. G. (2016). Transdiagnostic treatment of borderline personality disorder and comorbid disorders: A clinical replication series. Journal of Personality Disorders, 30(1),35-51. https://doi.org/10.1521/pedi_2015_29_179

Sauer-Zavala, S., Fournier, J. C., Steele, S. J., Woods, B. K., Wang, M., Farchione, T. J., \& Barlow, D. H. (2020). Does the unified protocol really change neuroticism? Results from 
a randomized trial. Psychological Medicine, 1-10.

https://doi.org/10.1017/S0033291720000975

Sauer-Zavala, S., Southward, M. W., \& Semcho, S. A. (2020). Integrating and differentiating personality and psychopathology in cognitive behavioral therapy. Journal of Personality. https://doi.org/10.1111/jopy.12602

Sleep, C. E., Lynam, D. R., \& Miller, J. D. (2021). A Comparison of the validity of very brief measures of the Big Five/Five-Factor Model of personality. Assessment, 28(3), 739-758. https://doi.org/10.1177/1073191120939160

Smits, M. L., Feenstra, D. J., Bales, D. L., de Vos, J., Lucas, Z., Verheul, R., \& Luyten, P. (2017). Subtypes of borderline personality disorder patients: A cluster-analytic approach. Borderline Personality Disorder and Emotion Dysregulation, 4, 16. https://doi.org/10.1186/s40479-017-0066-4

Soto, C. J., \& John, O. P. (2017). The next Big Five Inventory (BFI-2): Developing and assessing a hierarchical model with 15 facets to enhance bandwidth, fidelity, and predictive power. Journal of Personality and Social Psychology, 113(1), 117-143. https://doi.org/10.1037/pspp0000096

Southward, M. W., Cassiello-Robbins, C., Zelkowitz, R. L., \& Rosenthal, M. Z. (2020). Navigating the new landscape of value-based care: An example of increasing access, improving quality, and reducing costs using the Unified Protocol. The Behavior Therapist, 43(4), 134-137.

Tomko, R. L., Trull, T. J., Wood, P. K., \& Sher, K. J. (2014). Characteristics of borderline personality disorder in a community sample: Comorbidity, treatment utilization, and general functioning. Journal of Personality Disorders, 28(5), 734-750. 
https://doi.org/10.1521/pedi_2012_26_093

Trull, T. J., Useda, J. D., Conforti, K., \& Doan, B.-T. (1997). Borderline personality disorder features in nonclinical young adults: Two-year outcome. Journal of Abnormal Psychology, 106(2), 307-314.

van Zutphen, L., Siep, N., Jacob, G. A., Goebel, R., \& Arntz, A. (2015). Emotional sensitivity, emotion regulation and impulsivity in borderline personality disorder: A critical review of fMRI studies. Neuroscience \& Biobehavioral Reviews, 51, 64-76. https://doi.org/10.1016/j.neubiorev.2015.01.001

Vignarajah, B., \& Links, P. S. (2009). The clinical significance of co-morbid post-traumatic stress disorder and borderline personality disorder: Case study and literature review. Personality and Mental Health, 3(3), 217-224. https://doi.org/10.1002/pmh.89

Vogt, K. S., \& Norman, P. (2019). Is mentalization-based therapy effective in treating the symptoms of borderline personality disorder? A systematic review. Psychology and Psychotherapy: Theory, Research and Practice, 92(4), 441-464. https://doi.org/10.1111/papt.12194

Wall, K., Kerr, S., \& Sharp, C. (2021). Barriers to care for adolescents with borderline personality disorder. Current Opinion in Psychology, 37, 54-60. https://doi.org/10.1016/j.copsyc.2020.07.028

Weekers, L. C., Hutsebaut, J., \& Kamphuis, J. H. (2019). The Level of Personality Functioning Scale-Brief Form 2.0: Update of a brief instrument for assessing level of personality functioning. Personality and Mental Health, 13(1), 3-14. https://doi.org/10.1002/pmh.1434

Weiler, M. A., Val, E. R., Gaviria, M., Prasad, R. B., Lahmeyer, H. W., \& Rodgers, P. (1988). 
Panic disorder is borderline personality disorder. Psychiatric Journal of the University of Ottawa: Revue De Psychiatrie De l'Universite d'Ottawa, 13(3), 140-143.

Westen, D. (2000). Integrative psychotherapy: Integrating psychodynamic and cognitivebehavioral theory and technique. In Handbook of psychological change: Psychotherapy processes \& practices for the 21st century (pp. 217-242). John Wiley \& Sons Inc.

Whiteside, S. P., Lynam, D. R., Miller, J. D., \& Reynolds, S. K. (2005). Validation of the UPPS impulsive behaviour scale: A four-factor model of impulsivity. European Journal of Personality, 19(7), 559-574. https://doi.org/10.1002/per.556

Widiger, T. A., Bach, B., Chmielewski, M., Clark, L. A., DeYoung, C., Hopwood, C. J., Kotov, R., Krueger, R. F., Miller, J. D., Morey, L. C., Mullins-Sweatt, S. N., Patrick, C. J., Pincus, A. L., Samuel, D. B., Sellbom, M., South, S. C., Tackett, J. L., Watson, D., Waugh, M. H., ... Thomas, K. M. (2019). Criterion A of the AMPD in HiTOP. Journal of Personality Assessment, 101(4), 345-355. https://doi.org/10.1080/00223891.2018.1465431

Widiger, T. A., \& Mullins-Sweatt, S. N. (2010). Clinical utility of a dimensional model of personality disorder. Professional Psychology: Research and Practice, 41(6), 488-494. https://doi.org/10.1037/a0021694

Wolitzky-Taylor, K., Chung, B., Bearman, S. K., Arch, J., Grossman, J., Fenwick, K., LengnickHall, R., \& Miranda, J. (2019). Stakeholder Perceptions of the Barriers to Receiving and Delivering Exposure-Based Cognitive Behavioral Therapy for Anxiety Disorders in Adult Community Mental Health Settings. Community Mental Health Journal, 55(1), 8399. https://doi.org/10.1007/s10597-018-0250-z

Yeomans, F. E., \& Levy, K. N. (2002). An object relations perspective on borderline personality. 
Acta Neuropsychiatrica, 14(2), 76-80. https://doi.org/10.1034/j.16015215.2002.140205.x

Yen, S., Peters, J. R., Nishar, S., Grilo, C. M., Sanislow, C. A., Shea, M. T., Zanarini, M. C., McGlashan, T. H., Morey, L. C., \& Skodol, A. E. (2021). Association of Borderline Personality Disorder Criteria With Suicide Attempts: Findings From the Collaborative Longitudinal Study of Personality Disorders Over 10 Years of Follow-up. JAMA psychiatry, 78(2), 187-194. https://doi.org/10.1001/jamapsychiatry.2020.3598

Young, J. E., Klosko, J. S., \& Weishaar, M. E. (2006). Schema Therapy: A Practitioner's Guide. The Guilford Press.

Zanarini, M. C., Conkey, L. C., Temes, C. M., \& Fitzmaurice, and G. M. (2017). Randomized Controlled Trial of Web-Based Psychoeducation for Women With Borderline Personality Disorder. Psychoeducation for Borderline Personality Disorder, 78. https://doi.org/10.4088/JCP.16m11153

Zanarini, M. C., Weingeroff, J. L., Frankenburg, F. R., \& Fitzmaurice, G. M. (2015). Development of the self-report version of the Zanarini Rating Scale for Borderline Personality Disorder. Personality and Mental Health, 9(4), 243-249. https://doi.org/10.1002/pmh.1302

Zimmerman, M., \& Coryell, W. (1989). DSM-III personality disorder diagnoses in a nonpatient sample. Demographic correlates and comorbidity. Archives of General Psychiatry, 46(8), 682-689. 
Table 1

BPD Compass Skills and Goals

\begin{tabular}{|c|c|c|c|}
\hline Skills Domains & Workbook Chapters & $\begin{array}{l}\text { Number of } \\
\text { Sessions }\end{array}$ & Therapeutic Goal \\
\hline $\begin{array}{l}\text { Introductory } \\
\text { Content }\end{array}$ & $\begin{array}{l}\text { What is BPD? } \\
\text { About This Treatment }\end{array}$ & 1 & $\begin{array}{l}\text { - Review patient symptoms and conceptualize them within the three personality } \\
\text { dimensions associated with BPD } \\
\text { - Introduce the skills covered in the treatment }\end{array}$ \\
\hline Values Work & $\begin{array}{l}\text { Identifying Your Values } \\
\text { Approaching Your Values }\end{array}$ & 2 & $\begin{array}{l}\text { - Encourage patients to reflect on their values in various life domains } \\
\text { - Provide a framework for patients to monitor their (emotional, interpersonal, and } \\
\text { impulsive) triggers and evaluate whether their responses (feelings, thoughts, behaviors) } \\
\text { are in line with their values }\end{array}$ \\
\hline $\begin{array}{l}\text { Skills for } \\
\text { Thinking }\end{array}$ & $\begin{array}{l}\text { Cognitive Flexibility for } \\
\text { Emotions } \\
\text { Cognitive Flexibility for } \\
\text { Relationships } \\
\text { Cognitive Flexibility for } \\
\text { Impulses }\end{array}$ & $3-4$ & $\begin{array}{l}\text { - Encourage patients to evaluate their automatic thoughts (and generate alternative } \\
\text { responses) in emotion eliciting situations, as well as about emotions themselves } \\
\text { - Encourage patients to evaluate automatic thoughts about themselves and others (and } \\
\text { generate alternative responses), with specific attention to black-and-white thinking and } \\
\text { consideration of the varied ways one can trust another person } \\
\text { - Encourage patients to evaluate automatic thoughts about their ability to follow through on } \\
\text { goals, make cohesive plans, engage in rash actions in response to emotions, and } \\
\text { inappropriately seek out sensations. }\end{array}$ \\
\hline Skills for Doing & $\begin{array}{l}\text { Changing Emotional } \\
\text { Behaviors } \\
\text { Changing Relationship } \\
\text { Behaviors } \\
\text { Changing Impulsive } \\
\text { Behaviors }\end{array}$ & 6 & $\begin{array}{l}\text { - Identify patients' emotionally avoidant behaviors and plan alternative actions and } \\
\text { exposures that encourage approach-oriented behaviors. The goal is to facilitate new } \\
\text { learning that emotions can be tolerated } \\
\text { - Identify patients' unhelpful relationship behaviors and plan alternative actions and } \\
\text { exposures that allow patients to test hypotheses about others' motives. The goal is to } \\
\text { facilitate new learning that the patient can be safe in relationships } \\
\text { - Identify patients' impulsive behaviors in four domains (problems making plans, } \\
\text { problems following through, emotion-driven impulses, and sensation seeking) and plan } \\
\text { alternative actions/exposures for these areas. The goal is to facilitate new learning that } \\
\text { the urges will subside if not reinforced. }\end{array}$ \\
\hline Skills for Being & $\begin{array}{l}\text { Mindfulness of Emotions } \\
\text { Mindfulness of Relationships } \\
\text { Mindfulness of Impulses }\end{array}$ & $3-4$ & $\begin{array}{l}\text { - Cultivate a non-judgmental present-focused stance toward emotional experiences using } \\
\text { meditation and "in the moment" activities } \\
\text { - Cultivate a non-judgmental, present-focused stance toward other people (observing facial } \\
\text { expressions, body language, words used) using meditation and "in the moment" activities } \\
\text { - Cultivate a nonjudgmental, present-focused stance in response to impulses using } \\
\text { meditation and "in the moment" activities }\end{array}$ \\
\hline $\begin{array}{l}\text { Relapse } \\
\text { Prevention }\end{array}$ & $\begin{array}{l}\text { Recognizing } \\
\text { Accomplishments and } \\
\text { Looking to Your Future }\end{array}$ & 1 & $\begin{array}{l}\text { Evaluate progress (symptom improvement, skill cultivation) and create a plan for } \\
\text { continued practice after treatment has ended. }\end{array}$ \\
\hline
\end{tabular}


Table 2

Change in BPD, Anxiety, and Depressive Symptoms in Patients Treated With BPD Compass

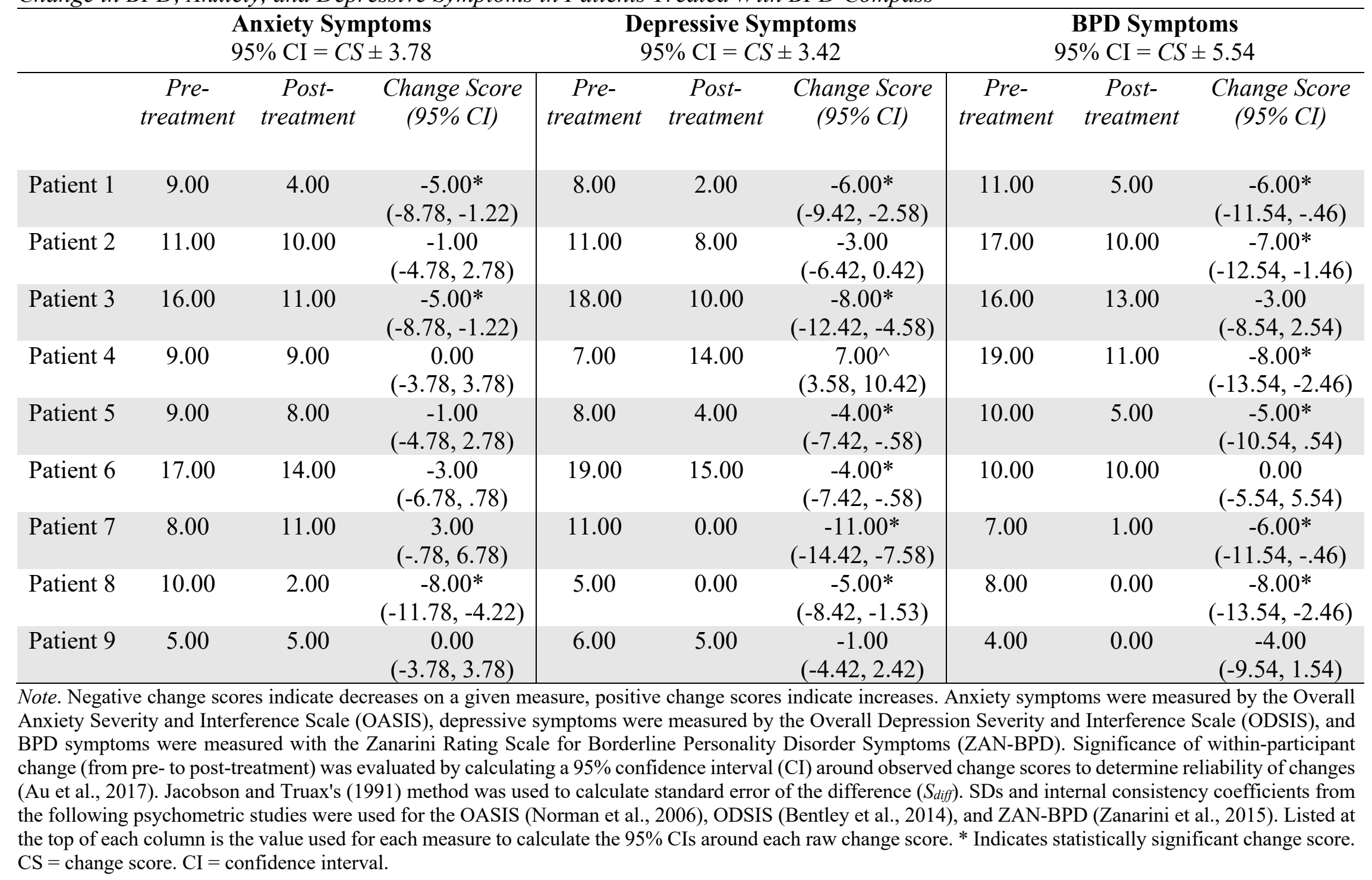




\section{Figure 1}
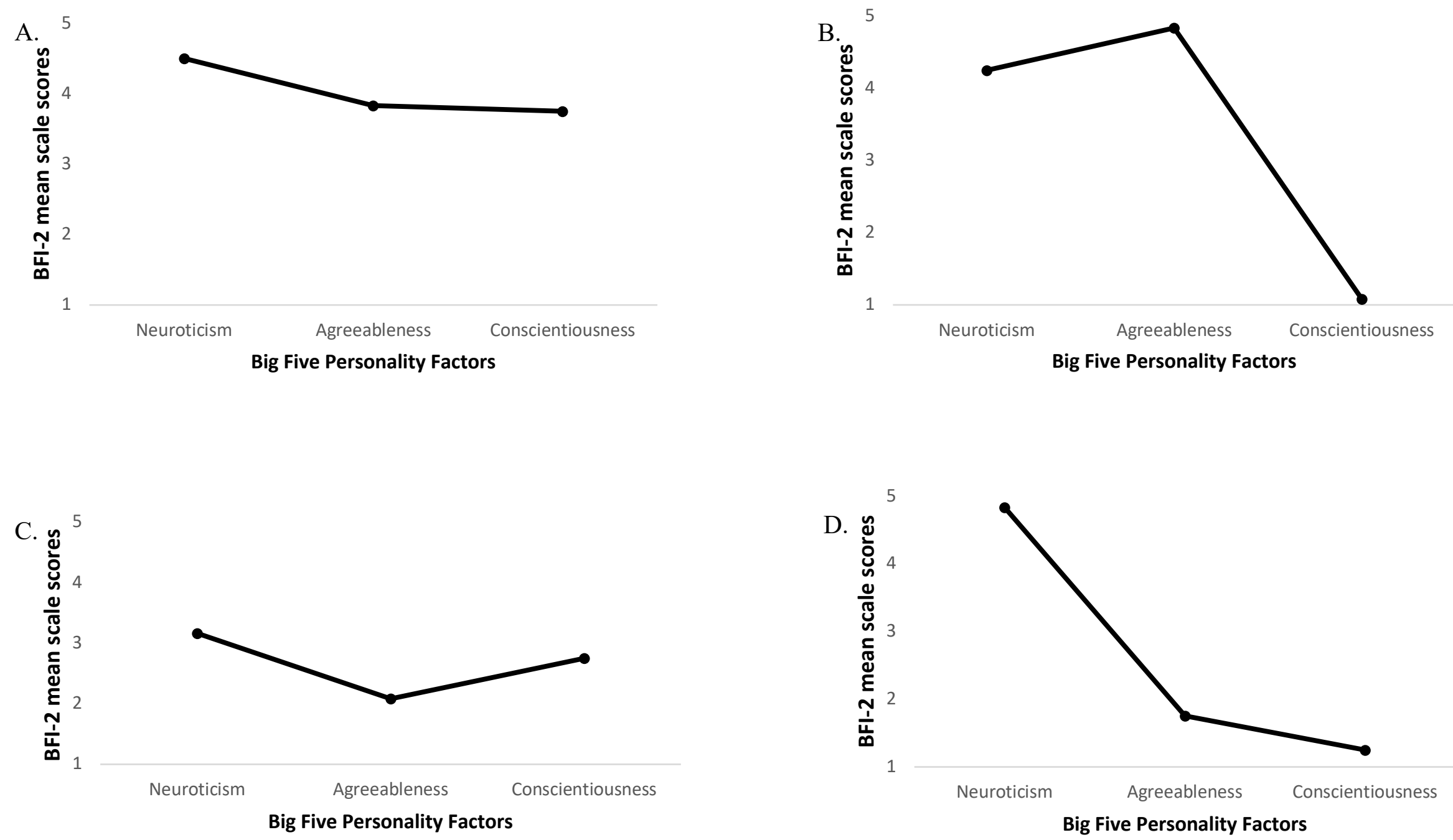

Figure 1. Five Factor Model profiles for four patients (A, B, C, D) diagnosed with borderline personality disorder. BFI-2 = Big Five Inventory-2. 